\title{
Gestão de custos no modelo de integração da estratégia de manufatura
}

\author{
Cost management in the integration model \\ of the manufacturing strategy
}

Milton Gomes PACHECO ${ }^{1}$

Felipe Araújo CALARGE²

\section{R E S U M O}

Os efeitos da globalização econômica exigem cada vez mais eficiência das políticas econômicas e financeiras das organizações. O fato dos meios de produção não mais dependerem de políticas locais ou regionais para fixar suas plantas industriais, tem exigido a percepção de que, para se conseguir ou manter as vantagens competitivas, são necessárias a combinação de fatores aliados entre estratégias e custos. As ferramentas de gestão da qualidade, incorporadas às unidades de negócios desde a década de 1960, permitiram grande avanço na aplicação de estratégias para formação de competência, com a gestão de custos sustentada pelas novas metodologias. Isso tem sido importante fator de competitividade. O uso possível de um modelo de integração incluindo a estratégia de competência e a gestão de custos, poderá contribuir de forma decisiva para o alinhamento das unidades de negócios às políticas corporativas.

Palavras-chave: vantagem competitiva, estratégia de competência, gestão de custos.

\section{A B S T R A C T}

The effects of the economic globalization increasingly demand more efficiency from the organizations' economic and financial policies. Once the production

\footnotetext{
${ }^{1}$ Diretor Geral, Faculdade Fleming. Rua Maria Umbelina Couto, 58, Guanabara, 13090-110, Campinas, SP, Brasil. Correspondência para/Correspondence to: M.G. PACHECO. E-mail: <pachecomg@directnet.com.br>.

2 Docente, Faculdade de Engenharia Mecânica e de Produção, Universidade Metodista de Piracicaba. Rodovia Iracemápolis, km 01, Santa Bárbara, 13450-000, Santa Bárbara D’Oeste, SP, Brasil. E-mail: <fcalarge@unimep.br>.

Recebido em 7/6/2004 e aceito para publicação em 9/11/2004.
} 
means no longer depend upon local or regional policies to settle industrial plants, it has demanded the perception that in order to get or to keep competitive advantages, it is necessary to combine factors, allied between strategies and costs. The quality-management tools, incorporated to the business units since the 1960's, allowed an great advance in the application of strategies to create competence, with cost management being supported by those new methodologies. This has been an important factor for competitiveness. The use possibility of an integration model comprising the competence strategy and the costs management will contribute in a decisive way to the alignment of the business units with the corporative policies.

Key words: competitive advantage, competence strategy, costs management.

\section{N T R O D U Ç Ã O}

Os dados produzidos por custos nas organizações têm suscitado constantes dúvidas sobre a viabilidade de serem um instrumento eficiente a ser empregado como fator de ajuste nas unidades de negócios afetadas por condições adversas de mercado, quando estas precisam utilizar mecanismos eficientes, no curto prazo, para manter o alinhamento às políticas corporativas. A principal fonte produtora de informações de custos nasceu com o nome de Contabilidade de Custos. Na visão de Hendriksen (1977), o grande crescimento da industrialização durante o século XIX, especialmente na Inglaterra e Estados Unidos, impulsionou a contabilidade de custos, dando grande significado às suas informações.

O sistema tradicional de custos tem prestado relevantes serviços na integração e coordenação da contabilidade de custos com a contabilidade financeira, por mais de dois séculos. Assim, as principais finalidades atendidas são: gerenciamento dos negócios, apuração de ganhos e perdas, para atender as legislações tributárias e societárias. Martins (2003) comenta que, com raras exceções, na maioria dos países, o fisco tem adotado a forma tradicional de mensuração das informações para a tributação dos resultados. Existem razões conceituais que têm sustentado a utilização dos métodos tradicionais e, como exemplo, pode-se citar o custo histórico, baseado no valor contábil quando atende à apuração dos ganhos e perdas e evita os efeitos de variação monetária, porque esse valor deve ser utilizado como reavaliação do capital da empresa (HENDRIKSEN; BREDA, 1999).

Os crescentes desafios da competitividade e globalização das atividades têm exigido novas práticas das organizações, sob o conceito de competência (FLEURY; FLEURY, 2001, p.64). Os sistemas tradicionais de custos não mais são suficientes para acompanhar a rapidez e a precisão das informações necessárias às gestões estratégicas de custos. Com a introdução do conceito de estratégia de manufatura para qualidade total, torna-se possível a obtenção da vantagem competitiva com foco na excelência empresarial.

Por ser um forte aliado no desenvolvimento dos conceitos de qualidade total, o just in time (JIT) ("bem-a-tempo"), pode ser aplicado também na gestão estratégica de custos no verdadeiro conceito de Cost Management Systems (CMS) (NAKAGAWA, 2000). As novas metodologias de custeios estão criando importantes alternativas nas tomadas de decisões. Martins (2003) comparou as metodologias de custeio variável, custeio por atividades, custeio alvo e custeio meta, com diversas aplicações para objetivos diferentes, como ferramenta na gestão estratégica de custos para encontrar o custo máximo suportável, que permita atingir o retorno desejável.

Os modelos de integração das diversas atividades das organizações podem ser um 
importante fator de equilíbrio para sustentação de políticas corporativas que privilegiem as estratégias na contemplação a longo prazo. As freqüentes mudanças conjunturais dificultam a manutenção do alinhamento às políticas pré-estabelecidas. A integração prioritária une os elos de ligação e contribui para o fortalecimento das diversas áreas da empresa.

\section{O planejamento estratégico versus estratégia de manufatura}

O planejamento estratégico da manufatura procura desenvolver condições para manutenção da vantagem competitiva; porém, não pode desconsiderar duas questões centrais. A primeira corresponde à atividade da indústria como fator de rentabilidade a longo prazo e às condições que determinam sua atratividade. A segunda questão a ser verificada é atender à estratégia competitiva, devendo-se utilizar as determinantes que sustentam a posição competitiva dentro da manufatura (PORTER, 1989).

O planejamento estratégico das unidades de negócios contempla, em sua estrutura básica, as metas definidas pela estratégia corporativa como elemento de regulamentação em suas atividades. Garvin (1993) comentou que a produção integra as possibilidades de incremento dos negócios, tanto na visão ampla quanto na contribuição isolada, para assegurar as operações suscetíveis aos impactos competitivos. O planejamento privilegia o foco nas metas de longo prazo, tornando-se ineficaz na aplicação de curto prazo, principalmente no atendimento das circunstâncias turbulentas que exigem decisões diárias.

A estratégia corporativa voltada para a conquista de mercado, determina que o planejamento estratégico tenha foco orientado para o mercado. As matrizes através de determinações corporativas estabelecem as declarações de missão, políticas, estratégias e metas para que as divisões e unidades de negócios preparem seus planos. Nas diversas circunstâncias, algumas corporações estimulam as unidades de negócios a instituírem suas metas e estratégias de vendas e lucro, enquanto outras estabelecem as metas para as unidades de negócios, mas permitem que estas desenvolvam suas próprias estratégias. Há ainda situações em que as corporações se envolvem profundamente nas estratégias de cada unidade de negócios (KOTLER, 2001) (Figura 1).

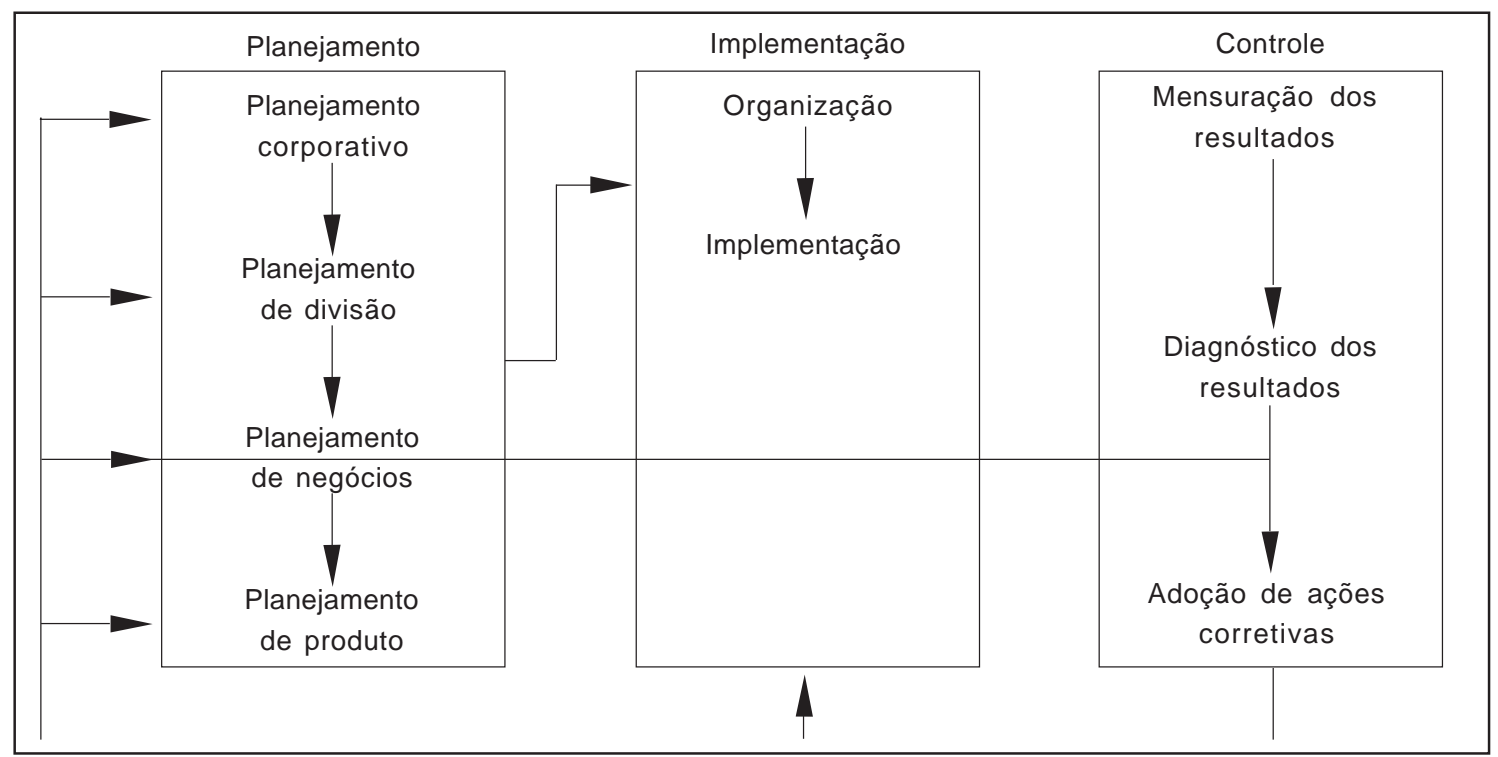

Figura 1. Processo de planejamento estratégico, sua implementação e controle. Fonte: Kotler (2001, p.87). 


\section{O sistema tradicional de custos na integração com a estratégia de manufatura}

O sistema tradicional de custos cumpre um importante papel nas organizações: serve de suporte dos registros das informações contábeis e atende sistematicamente princípios e conceitos jurídicos como base de sustentação da informação formal fidedigna. Dentro da competição globalizada, o grau de segurança na exatidão preconizado pela contabilidade de custos, não elimina as dificuldades para obtenção de informações que atendam aspectos societários e tributários e que, ao mesmo tempo, produzam elementos precisos para a decisão no gerenciamento dos negócios. As unidades de negócios enfrentam situações embaraçosas para manter o alinhamento com as políticas estratégicas determinadas pelas corporações. A integração das políticas de gestão estratégica de custos com a estratégia da manufatura pode ser utilizada como importante instrumento de ajuste para correções dos negócios em condições adversas, provocadas por turbulências na economia, situações estas que podem ser repetitivas no dia-a-dia, sem que as estratégias de manufatura tenham mecanismos de defesa para ajustar suas políticas.

\section{Sistema tradicional de custeio}

O sistema de custeio por absorção foi consagrado como o mais utilizado nos dias atuais entre os diversos sistemas, na apuração de custos dos produtos fabricados. Maher (2001) afirmou que, de acordo com os princípios contábeis geralmente aceitos, todos os custos relacionados com a produção, fixos e variáveis, compõem os custos dos produtos. Os demais itens gastos são chamados custos do período e não integram os produtos que permanecem no estoque. O sistema de custeio por absorção pode também ser desenvolvido sob as sistemáticas de custeio por ordem de fabricação e custeio por processo. A composição de custos é feita pelos custos diretos e indiretos. Tanto no custeio por ordem de fabricação, quanto no custeio por processo, a dinâmica de formação de custos aloca os custos diretos diretamente aos produtos e os custos indiretos são alocados por processos de rateio, quase sempre por critérios arbitrários, baseados em horas-máquina ou horas de mão-de-obra direta. A Figura 2 apresenta o fluxo do custeio por ordem de fabricação.

O custeio por processo normalmente é utilizado em empresas que têm o fluxo contínuo de produção, como Coca-Cola (refrigerantes),

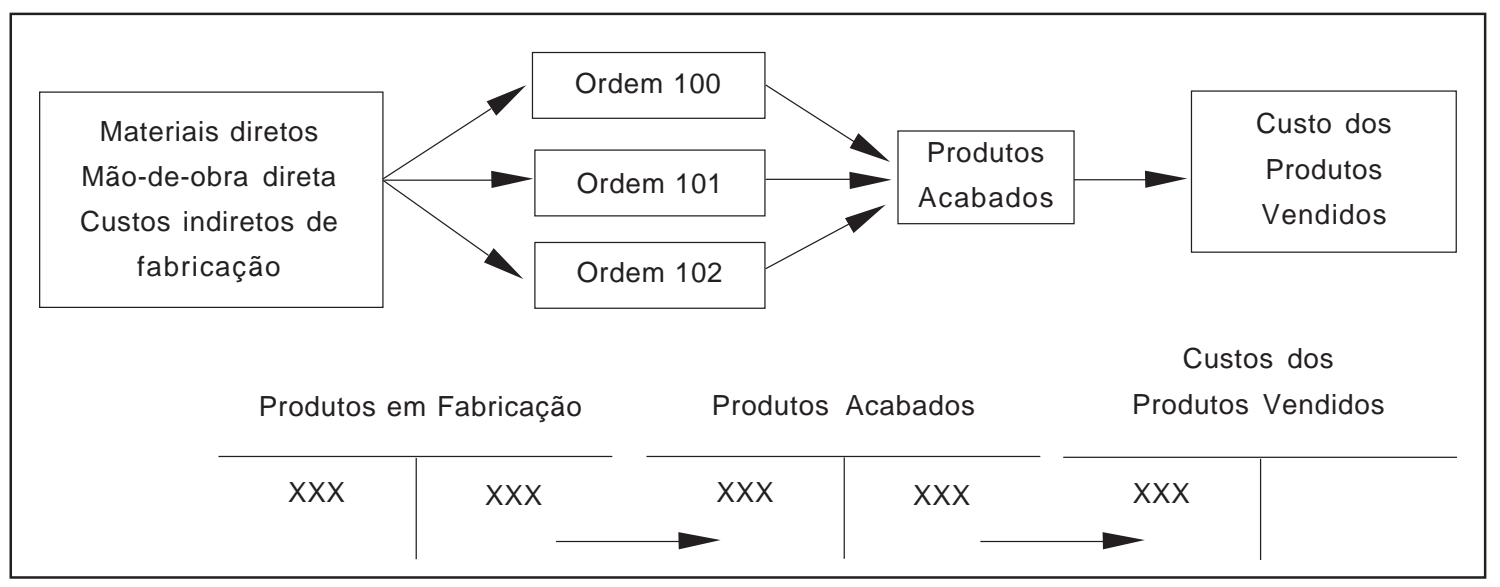

Figura 2. Fluxo de custeio por ordem de fabricação.

Adaptado de Maher (2001, p.160). 
Sherwin-Williams (tintas), Shell (petróleo) e Dow Chemical (produtos químicos) (MAHER, 2001). O custeio por processo está presente em grande parte das manufatureiras, porque atende a chamada produção contínua, caracterizada pelo processo produtivo de inúmeras atividades. A Figura 3 mostra a seqüência do fluxo desenvolvido para obtenção do custeio por processo.

Na visão de Nakagawa (2000), as tecnologias avançadas de produção não só vêm revolucionando os processos de produção no nível de chão de fábrica, mas vêm provocando significativas alterações nos padrões de custos. A incidência dos custos com materiais e mão-de-obra direta vem decrescendo, enquanto os gastos com Custos Indiretos de Fabricação (CIF), relacionados com depreciação, engenharia, informatização e outros, tornam-se cada dia mais representativos na formação do custo de produtos ou serviços, provocando distorções significativas nas alocações, aos produtos, dos custos indiretos de fabricação.

\section{Sistema de custeio variável (direto)}

O sistema de custeio variável (Figura 4) tem como princípio a separação dos custos indiretos de fabricação, em custos fixos e variáveis. Objetivando evitar a alocação na formação dos custos à parte que integra a base dos rateios, naturalmente os indiretos variáveis permitem alocação com bom grau de distribuição aos produtos ou serviços, evitando os critérios apoiados em conceitos arbitrários. O custeio variável surgiu como uma alternativa ao custeio por absorção, porque, com aquele critério, somente são agregados aos produtos os custos variáveis, adotando-se os custos fixos como custo do período, que naturalmente são transferidos para apuração do resultado (MARTINS, 2003).

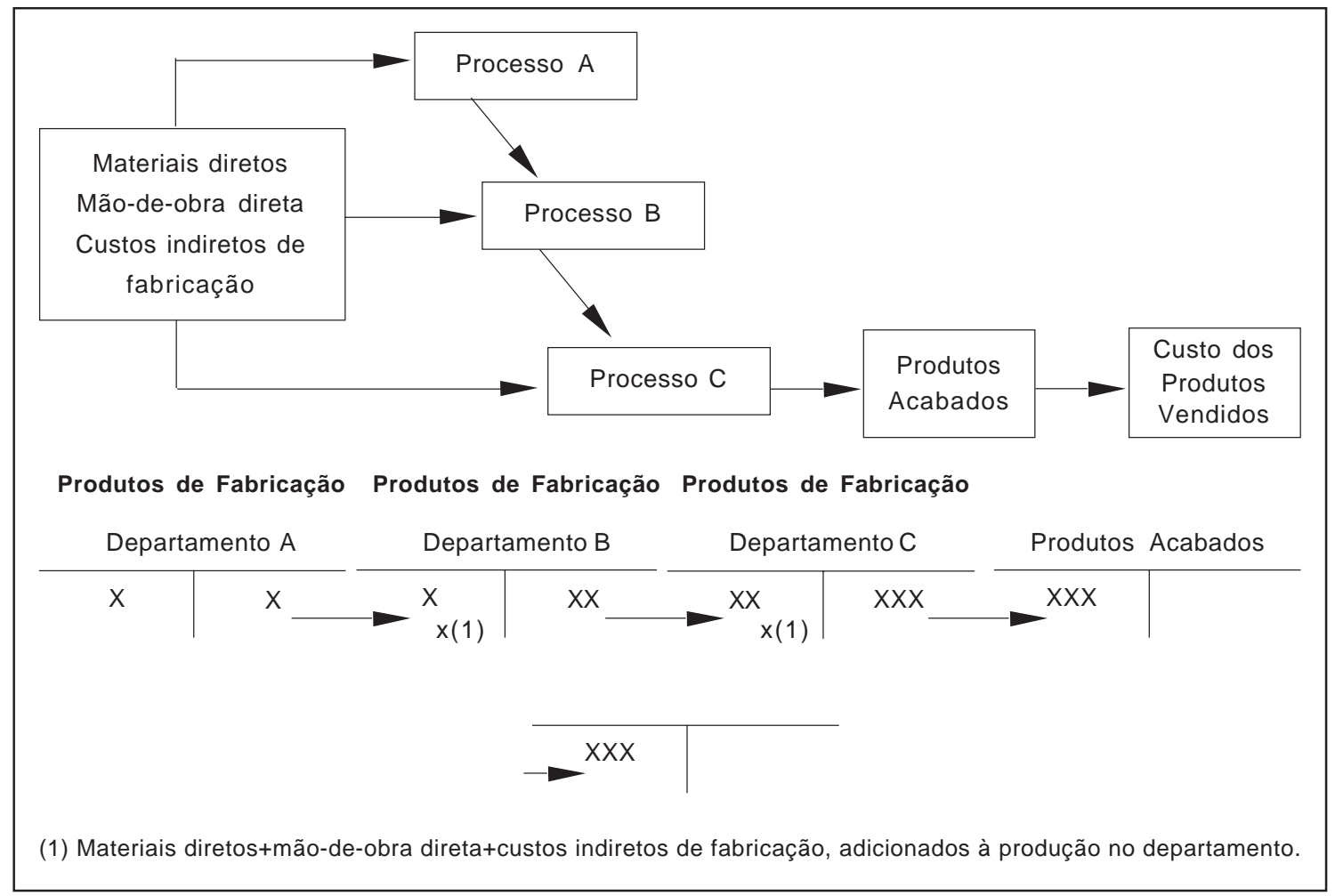

Figura 3. Fluxo de custeio por processo.

Adaptado de Maher (2001, p.160). 


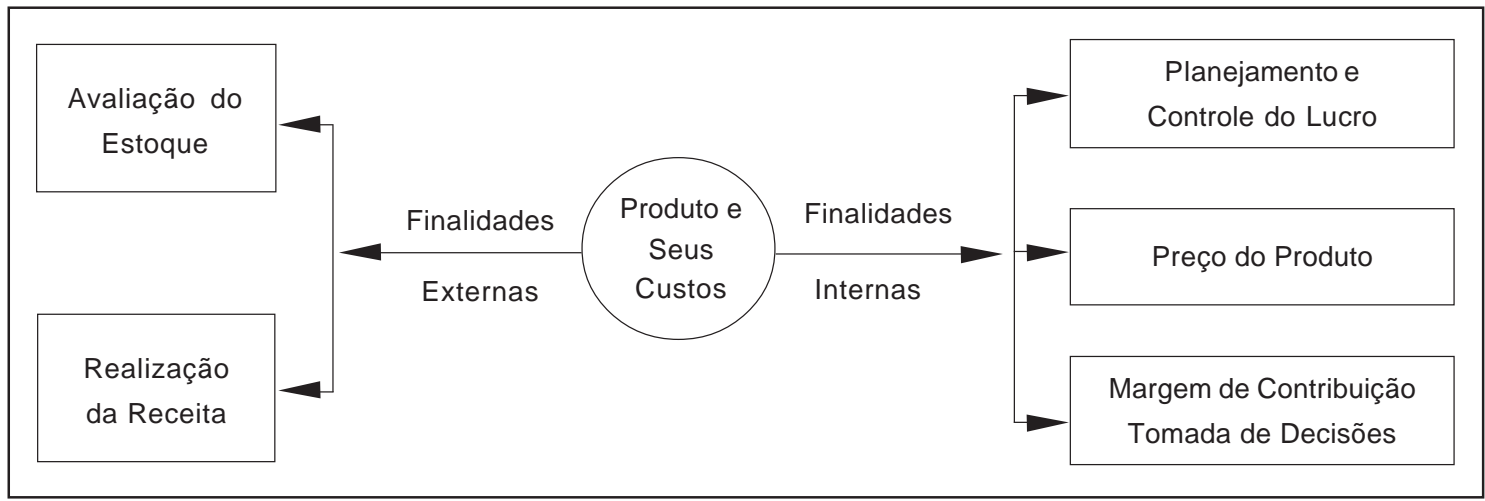

Figura 4. Aspectos do custeio variável. Adaptado de Maher (2001, p.166).

\section{Sistema de custo para tomada de decisões}

A filosofia do JIT ("bem a tempo") tem sido freqüentemente citada, pois, apesar de estar diretamente ligada à administração da qualidade total, os efeitos das políticas de comprar, fabricar produtos ou serviços refletem-se diretamente no custo dos produtos fabricados e vendidos. Os bons resultados com a gestão de custos estão intimamente ligados à capacidade da organização de utilizar recursos de maneira adequada para atingir seus objetivos, aumentando sua eficiência na obtenção dos resultados e utilizando menos recursos. A implantação do JIT pode trazer vários benefícios financeiros: menor volume de capital aplicado em estoques e em espaço de armazenagem; menores custos de produção, pela eliminação de atividades que não adicionam valor; evitar e/ou eliminar estoques obsoletos (MAHER, 2001). Nas organizações, a filosofia do JIT tem grandes reflexos nos custos, uma vez que ela busca eliminar os estoques desnecessários, de modo que os custos, quase na sua totalidade, sejam reconhecidos como incorridos no período de apuração dos resultados.

Buscando uma solução mais pragmática, a Teoria das Restrições (Quadro 1) surgiu como uma metodologia de análise, desenvolvida por Goldratt (1992), e propunha, no desenvolvimento da gestão de operações produtivas, a substituição das medidas físicas por avaliação de desempenho com utilização de medidas financeiras. A Teoria das Restrições considera obsoleta a Contabilidade de Custos, porque os procedimentos mandam alocar ao estoque o custo da mão-de-obra, da energia elétrica e dos gastos indiretos de fabricação. Essa teoria introduziu o conceito de análise financeira, possibilitando fazê-la por produto, somente com os materiais diretos, sem o efeito dos custos rateados.

\section{Gestão estratégica de custos}

A Gestão Estratégica de Custos tornouse uma prática obrigatória em todas as organizações que buscam implantar ou manter a vantagem competitiva de seus negócios. As corporações, em suas políticas de curto, médio e longo prazos, vêm adotando a gestão estratégica para suas atividades e para as atividades das unidades de negócios. Nakagawa (2000) fez menção da importância da criação do Consortium for Advanced Manufacturing Internationa/CAM-I, fundado em 1986 por uma equipe de pesquisadores, como um forum de desenvolvimento em projetos de pesquisas e gestão estratégica de custos, representando um marco importante na área da pesquisa. Os 
Quadro 1. Aplicação da teoria das restrições.

\begin{tabular}{|c|c|c|c|c|c|}
\hline & \multicolumn{2}{|c|}{ Produto X (0 Un.) } & \multicolumn{2}{|c|}{ Produto Y (352 Un.) } & \multirow{2}{*}{ Total } \\
\hline & Unitário & Subtotal & Unitário & Subtotal & \\
\hline Receitas & 610,00 & - & 600,00 & $211.200,00$ & $211.200,00$ \\
\hline (-) Custos com materiais diretos & $(480,00)$ & - & $(500,00)$ & $(176.000,00)$ & $(176.000,00)$ \\
\hline $\begin{array}{l}\text { Margem de Contribuição } \\
\text { (-) Custos indiretos }\end{array}$ & 130,00 & - & 100,00 & $35.200,00$ & $\begin{array}{l}35.200,00 \\
(32.000,00)\end{array}$ \\
\hline Lucro & & & & & $3.200,00$ \\
\hline
\end{tabular}

Adaptado de Bruni; Famá (2002, p.262).

Antes de 1970 as Empresas

Competiam Principalmente com base nos Custos

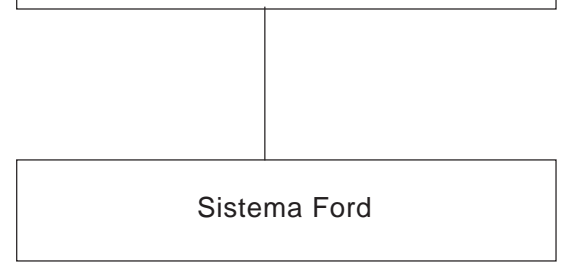

Atualmente as Empresas Precisam Competir com base na

Qualidade + Flexibilidade

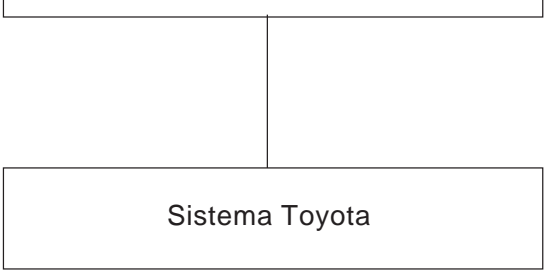

Figura 5. As empresas antes de 1970 e atualmente. Fonte: Nakagawa, (2000, p.33).

pesquisadores vêm utilizando os conceitos do Sistema de Gestão de Custos para gerenciamento estratégico, com significativos progressos desde o seu surgimento, apoiados nas tecnologias avançadas para atender a competição.

\section{Sistema de custeio por atividades (ABC)}

As novas metodologias com o emprego do custeio baseado em atividades e custeio alvo possibilitaram significativo progresso nos processos de apuração de custos dos produtos nas empresas, as quais buscam utilizar as informações de custos em suas tomadas de decisões, incorporando-os como fator de melhoria no desempenho (Figura 6).
Sztamfater e Brunstein (2000) apresentaram as vantagens do custeio integrado, ABC-EVA, afirmando que não somente geram informações mais precisas sobre o custo dos produtos, mas também permitem entender os processos da empresa com suas fontes de custos. Nakagawa (2001) afirmou que o Activity Based Costing (ABC) (Custo Baseado nas Atividades) é um método aplicado como análise dos custos para ratear os gastos utilizados para os fins que consumiram os recursos.

\section{Sistema de custeio alvo}

Ansari et al. (1997) comentou que o custeio alvo (Figura 7) representa um objetivo 
fundamental no gerenciamento do empreendimento, como um compreensivo sistema de planejamento do lucro. O custeio alvo está baseado sobre princípios fundamentais, segundo os quais o gerenciamento de custo começa antes da fabricação do produto. Os preços são formados pela competição de mercado, tendo como guia a voz do cliente. Mouritsen et al. (2001) sustentaram que os controles gerenciais entre-organizações são feitos pelos registros contábeis e pelo gerenciamento do custeio alvo, criando novas possibilidades de análises à intervenção gerencial. Os esforços incluem as atividades baseadas em custos e a melhoria no gerenciamento de processo contínuo, no contexto de como é formado o processo do modelo na aplicação desse instrumento.

\section{Modelo de integração}

Quase sempre, quando se precisa de boas idéias para construção de novas metodologias, surgem grandes incertezas, porque tudo aquilo que ainda não foi testado pode ser uma proposta cuja validade não se consiga comprovar. No prognóstico de Davenport et al. (2003), os realizadores de idéias percebem em sua cultura se o invento tende a ser experimental, porque, baseados na tecnologia, os indicadores de desempenho indicam se são precisos ou vagos.

A perspectiva de integração das políticas emanadas das corporações para as unidades de negócios, indica a possibilidade de fortalecimento das organizações nas superações de condições adversas, provocadas pelas turbulências na conjuntura econômica. O chamado Sistema de Reconfiguração de Manufaturas surgiu como um novo paradigma para regular o endereçamento de mudanças rápidas, que atende às constantes alterações de mercado e facilita a introdução de novos produtos (YIGIT; ALLAHVERDI, 2003).

\section{Breve revisão sobre modelos}

Segundo Have et al. (2003) o modelo de mudança propositada tem como princípio mais importante a harmonia integrada, porque a

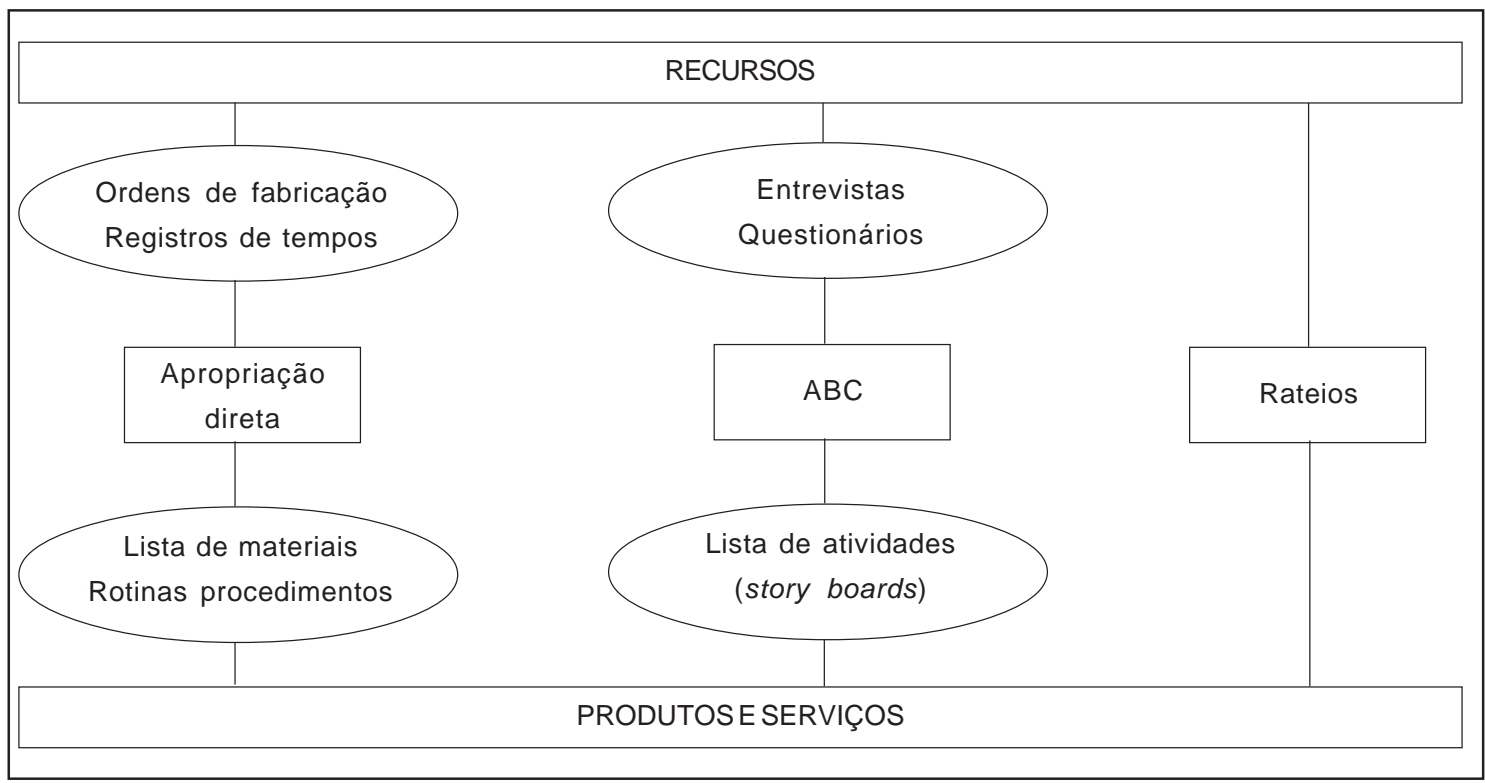

Figura 6. Custeio baseado em atividades (ABC).

Adaptado de Nakagawa (2001, p.47). 


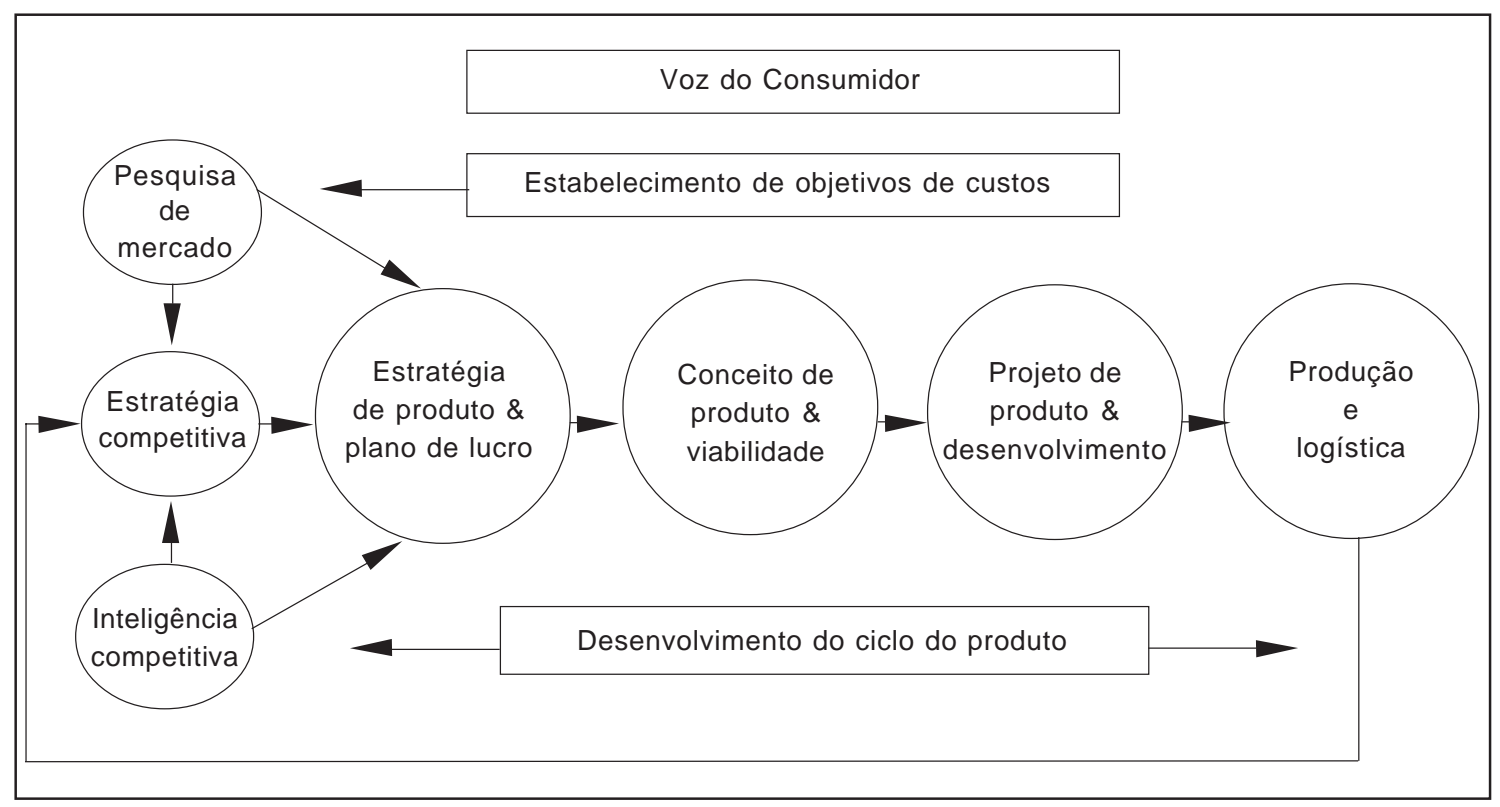

Figura 7. Contexto organizacional do custeio alvo (Target Costing). Adaptado de Ansari et al. (1997, p.14).

adaptação ao modo organizacional proporciona eficácia da organização na realização do atendimento de ambições e objetivos. O Balanced Scorecard (Cartão de Pontuação Balanceado) como modelo de integração na gestão organizacional permite a comparação entre as metas de desempenho fixadas pelas corporações e atende os níveis de desempenho como alvo nas novas iniciativas estratégicas. Segundo Kaplan e Norton (1997), o Balanced Scorecard tornou-se um novo sistema na integração das medidas derivadas da estratégia.

A principal razão para o administrador buscar, na construção de modelos, a solução de problemas ou melhorias em suas decisões, normalmente é dar suporte ao controle e à tomada de decisões nas organizações, permitindo que as demais pessoas envolvidas visualizem as possíveis conseqüências de uma solução ou decisão, na gestão dos negócios. Os modelos podem aplicar matemática e estatística para tentar solucionar dificuldades em questões complexas. Dentro do contexto da construção dos modelos, existem certas implicações, pois os métodos são baseados em abordagens racionais, num cenário que muitas vezes pode não ser tão racional (PIDD, 2001).

\section{Modelagem matemática}

A modelagem matemática (Figura 8) parte de um método científico na busca de aplicação de uma estratégia para um processo de aprendizagem. Na proposição de Bassanezi (2002), a ciência é uma atividade essencialmente desenvolvida pelo elemento humano, à procura de entender a natureza através de teorias próprias. A matemática e a lógica estão ligadas ao princípio de essencialidade formal, tratando-se de entes e idéias, abstratos ou interpretados, geralmente formados na mente humana. Os próprios objetos de estudos são construídos a partir de idéias matemáticas originadas pelas abstrações de situações empíricas, tanto naturais quanto sociais. A matemática está presente nas formações de modelos, porque resulta de sensibilidade, de estados emocionais diversos 
despertados pelo contato com a natureza, com os objetos de arte, com as estratégias e, principalmente, pelos desafios formulados como problemas. A utilização de modelagem proporciona técnicas próprias, que ajudam a desenvolver a capacidade de observação das formas de equilíbrio encontradas nas soluções.

O método de diagnóstico inicia-se com a análise da estrutura operacional da empresa, buscando como resposta quais instrumentos de gestão ela utiliza para formação ou sustentação da vantagem competitiva. Com base nessa identificação, é possível aplicar o plano de ação do modelo de integração (Quadro 2).
As empresas estão buscando soluções para tornar eficientes seus negócios e, nesse contexto, o diagnóstico tem como objetivo identificar as áreas que estão desalinhadas e não estão contribuindo com as políticas desenvolvidas pelas unidades de negócios. O processo de diagnóstico proposto tem o objetivo de verificar como está a ordenação das estratégias de manufatura e sua integração à gestão estratégica de custos, com o objetivo de aumentar o controle das ações de curto prazo, para a melhoria da eficiência nessas ações, buscando deste modo a vantagem competitiva.

Técnicas Matemáticas

Interpretação

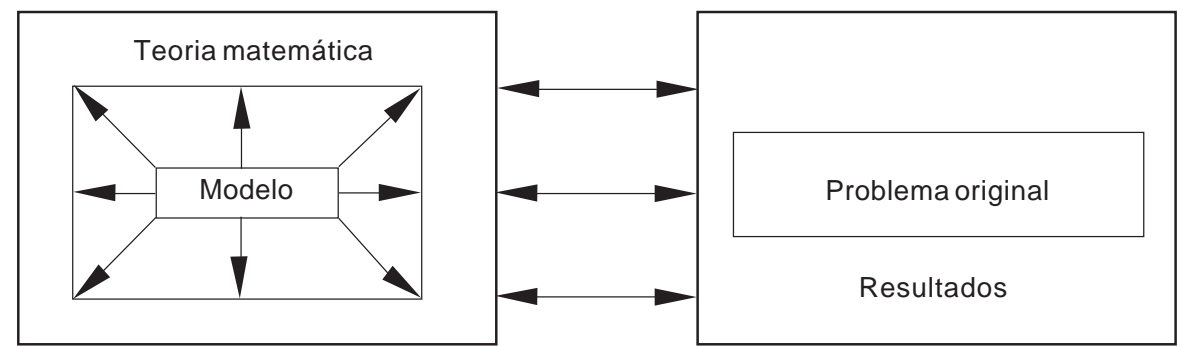

Figura 8. Processo de desenvolvimento de modelagem.

Adaptado de Bassanezi (2002, p.25).

Quadro 2. A intersecção dos sistemas tradicionais com a gestão estratégica.

\begin{tabular}{|c|c|c|c|c|c|c|c|c|}
\hline & A & B & C & D & $\mathbf{E}$ & $\mathbf{F}$ & G & $\mathbf{H}$ \\
\hline 1. Sistema Tradicional de Custos & $\mathrm{x}$ & $\mathrm{x}$ & & & & & & \\
\hline 2. Sistema de Custeio que Atende à Legislação Societária & $\mathrm{x}$ & $x$ & & & & & & \\
\hline 3. Sistema de Custeio que Atende à Legislação Tributária & $x$ & $\mathrm{x}$ & & & & & & \\
\hline 4. Sistema de Custeio Híbrido (JIT/Kaizen) & $\mathrm{x}$ & $\mathrm{x}$ & $\mathrm{x}$ & $\mathrm{x}$ & & & & $x$ \\
\hline 5. Gestão da Qualidade com ênfase em Custos & $x$ & $x$ & $\mathrm{x}$ & $x$ & $\mathrm{x}$ & $x$ & $x$ & $\mathrm{x}$ \\
\hline 6. Planejamento e Controle da Produção & & & & $\mathrm{x}$ & $\mathrm{x}$ & & & $\mathrm{x}$ \\
\hline 7. Gestão Estratégica de Custos & & & & & & $\mathrm{x}$ & $\mathrm{x}$ & \\
\hline 8. Formulação de Estratégia de Manufatura & & & & & & & & $x$ \\
\hline 9. Estratégia de Manufatura nas Pequenas e Médias Empresas & & & & & & & & $x$ \\
\hline 10. Estratégia Empresarial no Brasil & & & & & & & & $x$ \\
\hline A. Custeio por Ordem de Fabricação & & \multicolumn{7}{|c|}{ E. Teoria das Restrições } \\
\hline B. Custeio por Processo & & \multicolumn{7}{|c|}{ F. Custeio por Atividades $-A B C$} \\
\hline C. Custeio Variável (direto) & & \multicolumn{7}{|c|}{ G. Custeio Alvo } \\
\hline D. Just in Time - JIT & & \multicolumn{7}{|c|}{ H. Estratégia de Manufatura } \\
\hline
\end{tabular}


As vantagens que um processo de diagnóstico pode apresentar estão na relação do conhecimento das causas e da forma como a empresa faz a gestão de suas políticas de curto, médio e longo prazo, para estimular os instrumentos de ajuste na melhoria de eficiência.

As desvantagens que o processo de diagnóstico pode apresentar estão na pouca flexibilidade cultural que algumas organizações apresentam, inviabilizando as rápidas mudanças e podendo refletir de forma desastrosa nas tentativas de ajuste de curto prazo, como solução de correção de rota nas condições de conjunturas econômicas desfavoráveis.

\section{Proposta de um modelo de integração de gestão de custos e gestão de manufatura}

A gestão estratégica de custos vem desenvolvendo grandes esforços na construção de instrumentos de decisão no dia-a-dia das unidades de negócios, como suporte para manutenção das vantagens competitivas, enquanto as estratégias de manufatura dedicam-se na execução dos planos de longo prazo determinados pelas corporações. Para que as organizações possam maximizar o retorno de seus investimentos ao adotar o processo de integração, devem atender a seus clientes na plenitude de seus desejos, através de competência organizacional e minimização dos investimentos.

\section{Cadeia de valores em novos arranjos empresariais}

Na visão de Porter (1989) a cadeia de valores deve ser empregada olhando-se para a empresa como um todo. As vantagens da gestão de custos e da diferenciação no desempenho encontram-se na cadeia de atividades que a empresa pode executar no fornecimento de valores aos seus clientes. Porter elegeu cinco atividades primárias e quatro secundárias, objetivando formar a cadeia de valores para todas as empresas.

A caracterização da vantagem ou desvantagem pode ser identificada entre as atividades, formadas por cinco primárias e quatro secundárias. O conjunto de atividades determina a cadeia de valores para todas as empresas, porque é o conjunto de ações adotadas em suas operações, que sustentará as eficiências ou deficiências das organizações. A Figura 9 explicita a cadeia de valores sustentada pelo modelo de atividades secundárias e primárias.

A cadeia de valores tem sido utilizada como um importante instrumento na análise da vantagem competitiva; a proposta de Porter indica que a cadeia de valores deve ser adotada para separar as atividades das empresas nas cadeias de valores no maior nível de detalhe possível. À medida que se vai avançando nesse detalhamento, torna-se possível melhor conhecer como

\begin{tabular}{|l|l|c|c|c|c|}
\hline \multirow{2}{*}{ Atividades Secundárias } & \multicolumn{4}{|c|}{ Infra-estrutura da empresa } \\
\cline { 2 - 5 } & \multicolumn{4}{|c|}{ Gestão dos recursos humanos } \\
\cline { 2 - 5 } & \multicolumn{3}{|c|}{ Desenvolvimento de tecnologia } \\
\cline { 2 - 5 } & $\begin{array}{c}\text { Logística } \\
\text { Interna }\end{array}$ & Operações & $\begin{array}{c}\text { Logística } \\
\text { Externa }\end{array}$ & $\begin{array}{c}\text { Marketing } \\
\text { e Vendas }\end{array}$ & Serviço \\
\hline
\end{tabular}

Figura 9. Cadeia de valores no modelo de atividades secundárias e primárias.

Adaptado de Porter (1989, p.35). 
a empresa forma seu desempenho, e tal desagregação das atividades permite definir a estratégia genérica e as áreas mais sensíveis à aplicação da vantagem competitiva.

Porter apresentou o modelo de cadeia de valores em 1985 e a partir deste momento os consultores e formuladores de planejamentos estratégicos utilizaram-no para mapear os pontos fortes e fracos de cada organização. Nas alianças estratégicas, a cadeia de valores pode ser empregada para obter a visão geral nas combinações possíveis; por exemplo, há empresas fortes em produtos, outras em comercialização, logística ou serviços, mas, quando elas se juntam, formam uma superorganização na competição nos negócios.

Medir ou avaliar as forças competitivas nem sempre é uma tarefa fácil, principalmente na tentativa de mapear a cadeia de valores para avaliar de forma quantitativa. Novas funções precisam ser implementadas para que a Gestão de Custos venha a ser utilizada com eficiência na integração de todas as possibilidades para a criação de novos valores dentro das cadeias.

\section{O emprego da análise de SWOT nos planejamentos estratégicos}

Os modelos de integração devem ter como objetivo viabilizar a utilização de diferentes instrumentos de gestão para que a organização tenha condições de obter e manter as vantagens competitivas. A análise de Strengths, Weaknesses, Opportunities, (SWOT) estabelece as ações na posição da organização à luz de pontos fortes, pontos fracos, oportunidades e ameaças, e, naturalmente, há fatores internos e externos que surgem como resultado da dinâmica competitiva causada pelas circunstâncias de mercado (Figura 10). O planejamento estratégico é um valioso modelo para a auto-avaliação da administração (KOTLER, 2001).

O ponto mais importante da análise de SWOT sustenta-se na constituição de uma autoavaliação desenvolvida pela administração, que não pode subestimar as dificuldades, por utilizar elementos enganosamente simples. A identificação dos pontos fortes e fracos da empresa, no mesmo sentido em que avalia o impacto e a probabilidade das oportunidades e ameaças,

\begin{tabular}{|c|c|c|}
\hline & Pontos Fortes (F) & Pontos Fracos (Fr) \\
\hline $\begin{array}{l}\text { Oportunidades } \\
\qquad(\mathrm{O})\end{array}$ & $\begin{array}{l}\text { Estratégias de FO } \\
\text { Use os pontos fortes para tirar } \\
\text { vantagens das oportunidades }\end{array}$ & $\begin{array}{c}\text { Estratégias de FrO } \\
\text { Tire vantagem das oportunidades superando } \\
\text { os pontos fracos ou tornando-os relevantes. }\end{array}$ \\
\hline \multirow[t]{2}{*}{$\begin{array}{l}\text { Ameaças } \\
\text { (A) }\end{array}$} & $\begin{array}{l}\text { Estratégias de FA } \\
\text { Use os pontos fortes para evitar } \\
\text { ameaças }\end{array}$ & $\begin{array}{c}\text { Estratégias de FrA } \\
\text { Minimize os pontos fracos e evite as ameaças }\end{array}$ \\
\hline & \multicolumn{2}{|c|}{$\begin{array}{l}\text { Planejamento Estratégico de Negócios } \\
\text { - Análise do Ambiente Externo } \\
\text { - Oportunidades e Ameaças }\end{array}$} \\
\hline
\end{tabular}

Figura 10. Análise de SWOT para gestão estratégica.

Adaptado de Have et al. (2003, p.181). 
pode ser extremamente complexa; portanto, a classificação dos elementos de SWOT na aplicação do modelo não oferece ajuda para a aplicação de tarefa complicada na tradução das alternativas estratégicas. Quando os analistas fazem suposições incorretas na avaliação dos elementos, levam a administração a hesitar na escolha de uma, dentre as várias alternativas estratégicas; isto, além de dar lugar às decisões inadequadas, resulta em atrasos pelas naturais inseguranças que o processo pode apresentar.

\section{O modelo de mudança propositada na gestão dos negócios}

O modelo apoia-se no conceito segundo o qual os gerentes gerais são responsáveis por "tudo" em uma organização. As lideranças executivas devem perguntar-se quais ações precisam ser tomadas para que as execuções sejam bem feitas, no sentido de assegurar seus objetivos. Na proposta de Bower (2000), o domínio da mudança propositada define o que deve ser e como deve ser desenvolvido. Significa uma conquista dos gerentes gerais para o papel de arquitetos, construtores ou elaboradores da organização. A integração é a chave no modelo de mudança propositada, porque a interpretação da organização exige que tudo esteja perfeitamente adaptado a esse objetivo.

Há quatro processos de gestão que, desenvolvidos simultaneamente, formam um conjunto distinto de organização em direção, consistência, coerência e realimentação. O equacionamento organizacional constitui a espinha dorsal desses processos de gestão.

- Direção: A missão e os valores fazem parte das escolhas da organização e de suas metas comuns.

- Consistência: Os objetivos, as tarefas e os padrões comportamentais sustentam a tradução vertical da meta comum e dos valores organizacionais.
- Coerência: É a base da coordenação horizontal que define processos, cadeias, empresas, departamentos e pessoas, na junção das estruturas, dos sistemas e das competências.

- Realimentação: Sustenta o arranjo da organização no processo de aprendizado em intervalos de tempo variáveis.

A realimentação deve ser dinâmica, enquanto direção, consistência e coerência estabilizadoras. Para que os objetivos sejam alcançados, torna-se necessário que os elementos e recursos subjacentes estejam integrados e interativos. A Figura 11 revela o sentido de aplicação do modelo.

O modelo está dimensionado para ser empregado em processos de gestão que precisam de impulsos fortes nas ações e intervenções objetivas da gestão da organização. Isso pode ser feito pela congruência integrada, com a interpretação de que tudo pode ser adaptado de modo organizado e disciplinado, sob o controle do gerente geral. A visão da organização deve ser de longo prazo, determinada pela direção com a formulação de uma estratégia com gestão explícita, para formar competência. O princípio da formação de competência enfatiza que a gestão deve ser marcada por incentivos e valorização no desenvolvimento e comprometimento das pessoas, com a contrapartida de exigência crescente de resultados (FLEURY; FLEURY, 2001).

O modelo é sustentado por um princípio importante, a congruência integrada: quanto maior o interesse e a adaptação ao processo organizacional, maior a probabilidade de serem realizadas as ambições e objetivos da empresa. O modelo tem por objetivos ser funcional, tanto nas manufaturas dinâmicas, quanto nas estáveis. $\mathrm{Na}$ fase de implantação, a organização deve estar preparada para: crise mínima, mudança máxima e comprometimento máximo da administração. As alocações de pessoas e recursos devem estar bem dimensionadas dentro das possibilidades estratégicas, como ponto forte das mudanças. 


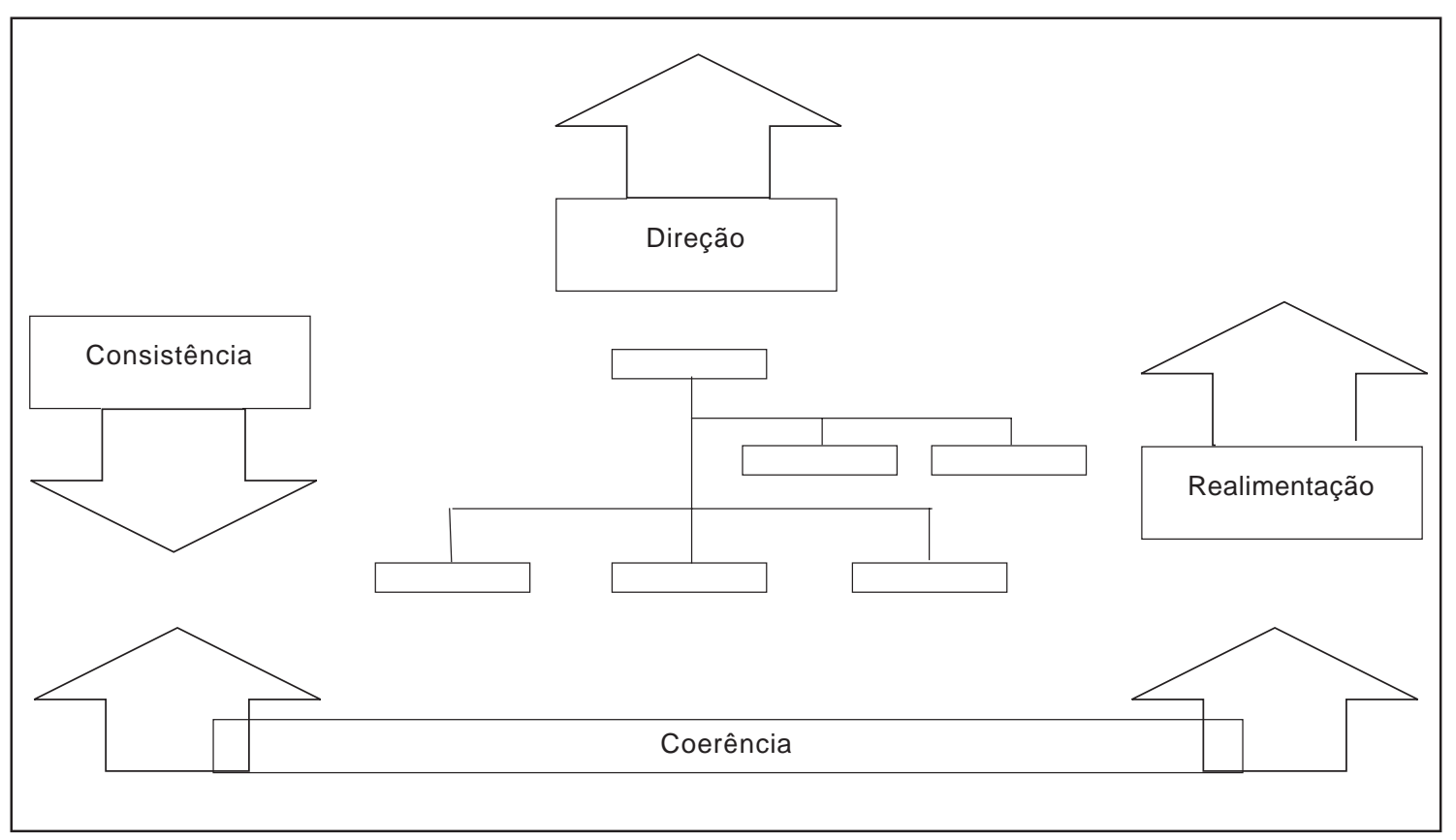

Figura 11. Modelo de mudanças propositadas.

Adaptado de Have et al. (2003, p.163).

\section{Gestão baseada em valor (VBM - value-based management)}

Este modelo emprega o método da gestão integrada e busca a maximização do valor para o acionista; para tanto, utiliza o planejamento, a avaliação, a compensação e a comunicação organizacional, ligados às recompensas pelo desempenho, objetivando satisfazer o conceito de valor agregado para os acionistas, visto que, nas corporações, a pulverização do seu controle acionário tornou-se uma situação delicada e sua sobrevivência depende cada vez mais da sua habilidade de criar valor (COPELAND et al., 2002).

A gestão baseada em valor concentra sua discussão em três áreas de aplicação de medidas de análise econômica e financeira, questionando os seguintes aspectos:

a) Devem as organizações utilizar diferentes medidas de valor?

b) Que influência os gestores, em diferentes níveis, têm sobre a criação de valor? c) Em qual extensão a remuneração deve ser diretamente ligada à criação de valor?

A implantação de gestão baseada em valor baseia-se no entendimento de que, em empresas diferentes, utilizam-se conceitos diferentes na medição do desempenho e na remuneração nele baseada, tendo-se como resultado final o significado do compromisso entre justeza e simplicidade.

O modo de quantificação dos geradores de valor e a unificação de modo mensurável na integração, exigem o compromisso das equipes em seus diversos níveis. A falta de controle dos executivos sobre determinada medida essencial de valor - por exemplo, o preço da ação -, determina um correto dimensionamento dos geradores de valores, cabendo à organização definir quais serão utilizados para cada nível de gestão, sabendo-se que os principais geradores de valor são o faturamento das vendas, as margens operacionais, as taxas de estrutura de capital e as taxas de capital de giro, entre outros. Toda a ação depende das responsabilidades funcionais 
Passo 1 Entenda os criadores de valor de uma empresa

Invista nas atividades em que a empresa pode ter margens de crescimento mais altas

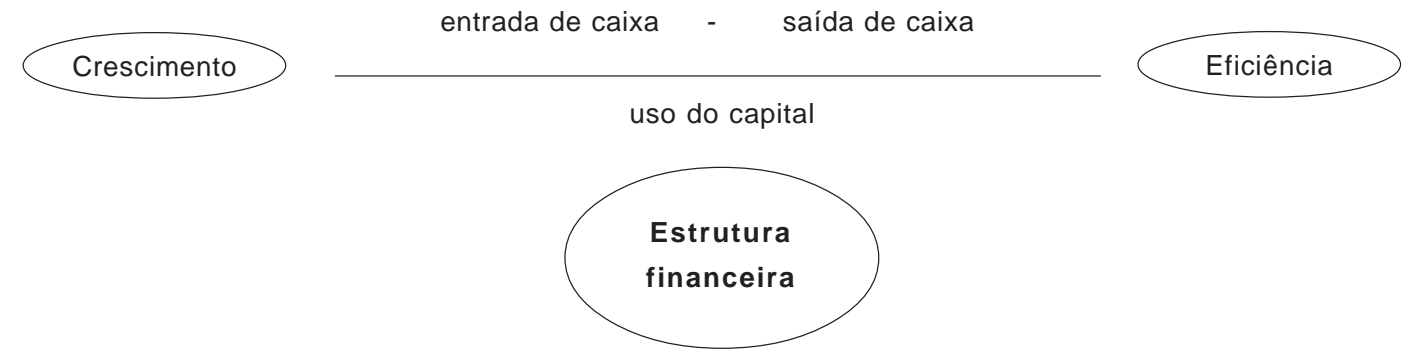

para produzir uma taxa de retorno que

exceda o seu custo de capital

Passo 2 Determine os geradores de valor e os destruidores de valor

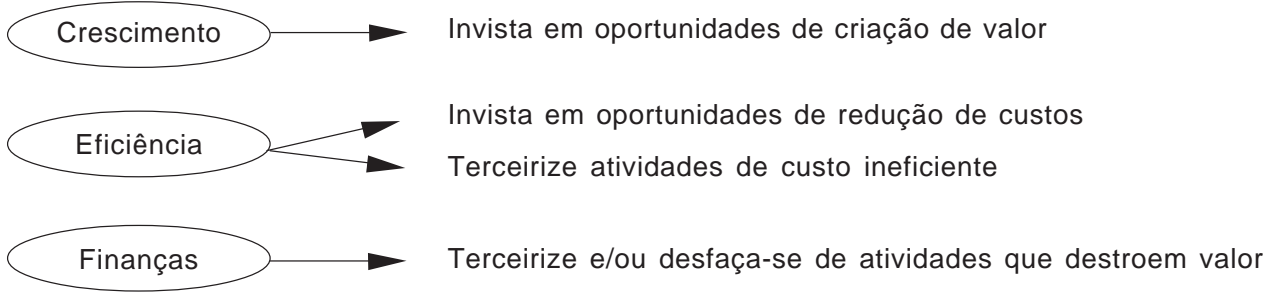

Figura 12. Modelo de gestão criadores/geradores de valor.

Adaptado de Have et al. (2003, p.184).

que podem exigir-se das equipes: quando os executivos perdem o controle das ações, os reflexos voltam-se contra o processo. Para minimizar esse tipo de reflexo é importante determinarem-se os valores de cada nível da gestão, tendo como objetivo a participação responsável de todos os níveis hierárquicos da organização. A Figura 12 explicita como entender e determinar os criadores de valores.

Segundo Porter e Montgomery (1998), um dos objetivos principais do planejamento estratégico corporativo é criar valor para os acionistas. O planejamento com foco na tomada de decisões gerenciais, permite a alocação de recursos corporativos de maneira mais produtiva e lucrativa. Essa ação presume que o planejamento estratégico seja desenvolvido com crescimento suficiente para atender os lucros desejados por ação (EPS - earnings per share). A materialização do plano garante $o$ aumento do valor das ações para os acionistas da empresa, diferentemente do comportamento das ações no mercado, que, muitas vezes, por razões do dinamismo do mercado de capitais, têm comportamentos diversos.

A Gestão Baseada em Valor não pode ser vista apenas como um conjunto de indicadores financeiros de uma empresa. Ela tem como proposta viabilizar uma constante ação administrativa no uso dos recursos, provocando mudança fundamental na maneira de pensar sobre crescimento, planejamento e lucros. A aplicação exige total compromisso do conselho, dos executivos, dos gerentes, além dos demais níveis da organização, para obter-se sucesso na criação de valor para os acionistas.

\section{CONSIDERAÇÕ ES FINAIS}

A globalização da concorrência vem exercendo enorme influência no desempenho 
econômico dos empreendimentos, principalmente daqueles que desconsideram o foco no cliente como meio de garantir o retorno dos investimentos.

A inclusão da cadeia de valores nas políticas estratégicas permite criar e sustentar as vantagens competitivas. Isto pode tornar-se um fator de sobrevivência nas condições adversas, quando os impactos negativos provocados pelas turbulências econômicas precisam ser diluídos em vários extratos de cada cadeia, como fator de sustentação. Como exemplo, cita-se a nova forma de criar as unidades de negócios no Brasil, por parte da indústria automobilística, que, através de parcerias em consórcio com os fornecedores, realizam a montagem dos veículos. A outra modalidade é feita pelo compartilhamento, em condomínio, da mesma área de fabricação e montagem dos veículos, e das autopeças pelos fornecedores.

$\mathrm{Na}$ busca de instrumentos eficazes, as unidades de negócios precisam de mecanismos que contemplem soluções de curto, médio e longo prazo, permitindo a estabilidade econômica como mecanismo de superação das crises conjunturais.

A gestão de custos, como função de equilíbrio no dia-a-dia das organizações, precisa ser mais bem explorada como forma de integrar a estratégia da manufatura, dentro da visão de longo prazo que faz parte das políticas determinadas pelas corporações.

O modelo de integração busca proporcionar a aplicação de ferramentas de ajustes para melhorar e assegurar desempenhos mais uniformes das unidades de negócios, permitindo constantes correções e ajustes no planejamento e controle da produção, com o objetivo de garantir o retorno do capital investido e a constante estabilidade no cash flow - o fluxo de caixa. O bom planejamento e o controle do fluxo de caixa podem garantir a sobrevivência das empresas, mesmo nas condições provocadas pelos reflexos desfavoráveis das eventuais alterações das conjunturas econômicas.

O modelo de mudança propositada utiliza a congruência integrada, interpretada com os objetivos de fazer com que tudo se adapte à organização estabelecida, integrando todas as dificuldades, componentes e disciplinas sob o controle do gerente geral. Esse conceito significa que as diversas partes componentes precisam estar em harmonia na organização, para que os esforços atendam os mesmos objetivos. O destaque dado ao principal executivo das organizações é a chave do sucesso, na aplicação desse modelo de integração.

A gestão baseada em valor não pode ser considerada como um conjunto de indicadores financeiros da empresa, porque tem como objetivo desenvolver ação contínua nas decisões administrativas para o uso dos recursos. A mudança fundamental está na maneira de pensar para obter crescimento, planejamento e lucros. Para ter sucesso, torna-se necessário comprometimento com as prioridades do conselho, dos executivos, da gerência, além das prioridades dos demais níveis da organização. Esse modelo valoriza a capacidade do elemento humano nas organizações.

Os modelos de gestão que adotam a integração da organização em torno de objetivos maiores, têm demonstrado maior coesão e consistência para suportar os efeitos da concorrência globalizada, quando buscam criar e manter as vantagens competitivas. $O$ consumidor é o grande beneficiado pelo esforço das organizações na busca de eficiência, estimuladas pela competição da globalização econômica.

Avaliando o efeito da turbulência econômica nas organizações, torna-se possível compreender a necessidade de integração das ações de curto, médio e longo prazo, como fator de grande importância para assegurar decisões eficazes nas tomadas de decisões das unidades de negócios. 


\section{R E F E R Ê N C I A S}

ANSARI, S.L.; BELL, J.E.; THE CAM-I. Target costing: the next frontier in strategic cost management. Chicago: Irwin, 1997. p.14-23.

BASSANEZI, R.C. Ensino-Aprendizagem com modelagem matemática. São Paulo: Contexto, 2002. p.25.

BOWER, J.L. The purpose of change, a commentary on Jensen e Senge. In: BEER, M.; NOHRUNA, N. Breaking the code of change. Boston: Harvard Business School Press, 2000. p.83-95.

BRUNI, A.L.; FAMÁ, R. Gestão de custos e formação de preços. São Paulo: Atlas, 2002. p.262.

COPELAND, T.D.; KOLLER, T.; MURRIN, J. Avaliação de Empresas - valuation: calculando e gerenciando o valor das empresas. 3.ed. São Paulo: Makrin Books, 2002.

DAVENPORT, T.M.; WILSON, H.J.; PRUSAK, L. Vencendo com as melhores idéias. Rio de Janeiro: Campus, 2003. p.59-77.

FLEURY, A.; FLEURY, M.T.L. Estratégias empresariais e formação de competência. 2.ed. São Paulo: Atlas, 2001. p.65.

GARVIN, D.A. Manufacturing Strategic Planning. California Management Review, Summer, v.35, n.4, p.85-105, 1993.

GOLDRATT, E.M.; COX, J. Meta. 2.ed. São Paulo: Educator, 1992.

HAVE, S.T.; HAVE, W.T.; ELST, M. Modelos de Gestão. São Paulo: Prentice Hall, 2003. p.162-184.

HENDRIKSEN, E.S. Accounting theory. 3rd. Illinois: Homewood, 1977. p.41.

HENDRIKSEN, E.S.; BREDA, M.F.V. Teoria da contabilidade. 5.ed. São Paulo: Atlas, 1999, p.306.

KAPLAN, R.S.; NORTON, D.P. A Estratégia em ação. 16.ed. Rio de Janeiro: Campus, 1997.
KOTLER, P. Administração de marketing. 10.ed. São Paulo: Prentice Hall, 2001. p.86-87.

MAHER, M. Contabilidade de custos. São Paulo: Atlas, 2001. p.160-166.

MARTINS, E. Contabilidade de custos. 9.ed. São Paulo: Atlas, 2003. p.286-301.

MOURITSEN, J.; HANSEN, A.; HANSEN, C.O. Inter-organizational controls and organization competences: episodes around target cost management analisys and open book accounting. Management Accounting Research, v.12, p.221-244, 2001.

NAKAGAWA, M. Gestão estratégica de custos. São Paulo: Atlas, 2000. p.33-57.

NAKAGAWA, M. ABC custeio baseado em atividades. 2.ed. São Paulo: Atlas, 2001. p.33-47.

PIDD, M. Modelagem empresarial: ferramentas para tomada de decisões. Porto Alegre: Bookman, 2001.

PORTER, M.E. Vantagem competitiva. Rio de Janeiro: Campus, 1989. p.35-36.

PORTER, M.E.; MONTGOMERY, C.A. Estratégia a busca da vantagem competitiva. Rio de Janeiro: Campus, 1998, p.360-396.

SZTAMFATER, T.; BRUNSTEIN, I. Considerações sobre o custeio integrado ABC-EVA e aplicação prática em uma confecção. Boletin Técnico da Escola Politécnica da USP, BT/PRO/078, p.1-18, 2000.

YIGIT, A.S.; ALLAHVERDI, A. Optimal selection or module instances for modular products in reconfigurable manufacturing systems. International Journal of Production Research, v.41, n.17, p.4063-4074, 2003. 
